\title{
Ultrasonographic aspects of the uterus and ovaries of bitches during the estrous cycle - paper review
}

Aspectos ultrassonográficos do útero e ovários de cadelas durante o ciclo estral - revisão de literatura

\author{
Luiz Paulo Nogueira Aires ${ }^{1 *}$, Letícia Pavan ${ }^{1}$, Beatriz Gasser ${ }^{1}$, Priscila Silva ${ }^{1}$, Marjury Cristina \\ Maronezi $^{1}$, Priscila Del Aguila da Silva ${ }^{1}$, Marcus Vinícius Silveira ${ }^{1}$, Victor José Correia Santos ${ }^{1}$, \\ Luciana Cristina Padilha-Nakaghi ${ }^{1}$, Ricardo Pozzobon ${ }^{2}$, Marcus Antônio Rossi Feliciano ${ }^{1,2}$ \\ ${ }^{1}$ Faculdade de Ciências Agrárias e Veterinárias - Universidade Estadual Paulista "Júlio de Mesquita Filho" \\ (FCAV/UNESP) - Jaboticabal, SP, Brasil \\ ${ }^{2}$ Universidade Federal de Santa Maria (UFSM) - Santa Maria, RS, Brasil \\ Via de Acesso Prof. Paulo Donato Castellane s/n - Jaboticabal/SP - CEP 14884-900
}

\begin{abstract}
The ultrasonographic exam is of great value in animal reproduction and veterinary obstetrics, because it allows gestational diagnosis and monitoring, as well as the evaluation of the female reproductive system, providing diagnosis of the reproductive state and estrous phase of females. One of the techniques that has been employed in the field of theriogenology is the Doppler Mode, which allows qualitative and quantitative evaluation of the hemodynamics of reproductive organs. Several studies were carried out in attempt to elucidate the ultrasonographic aspect of the uterus and ovaries of bitches during the different phases of the estrous cycle in B mode and Doppler mode. The objective of the present study is to review the information present in the literature regarding the sonographic changes of the reproductive organs of bitches during the different hormonal phases.
\end{abstract}

Keywords: Canine, Follicular Phase, Luteal Phase, Hemodynamics, Doppler, Hormonal Changes.

\section{Resumo}

O exame ultrassonográfico tem grande importancia na reprodução animal e obstetrícia veterinária, pois permite o diagnóstico e acompanhamento gestacional, bem como a avaliação do sistema reprodutor, proporcionando o diagnóstico do status reprodutivo e fase do ciclo estral. Uma das técnicas ultrassonográficas que vêm sendo empregadas no ramo da teriogenologia é o modo Doppler, que permite avaliações qualitativas e quantitativas da hemodinâmica dos órgãos da reprodução. Diversos estudos foram realizados na tentativa de elucidar o aspecto ultrassonográfico do útero e dos ovários das cadelas durante as diferentes fases do ciclo estral ao modo-B e ao modo Doppler. O presente trabalho tem como objetivo revisar as informações presentes na literatura a respeito das mudanças ultrassonográficas dos órgãos reprodutores da cadela durante as diferentes fases hormonais.

Palavras-chave: Canino, Fase Folicular, Fase Luteal, Hemodinâmica, Doppler, Mudanças Hormonais.

\section{Introduction}

Ultrasonography is an important imaging tool in animal reproduction and veterinary obstetrics and is routinely used in clinical practice for detecting and monitoring pregnancy, besides aiding in the study of ovarian and uterine characteristic of bitches, collaborating in the diagnosis of reproductive status and estrous cycle phase (Barbosa et al., 2013).

Among the different ultrasound techniques available, the Doppler mode stands out, which is a technique based on the interaction of sound with moving particles, leading to a change in frequency of the received echoes (Boote, 2003). This tool, associated with the two-dimensional mode, provides information regarding the vascular architecture, presence of flow, its direction and hemodynamic characteristics (Carvalho et al., 2008).

${ }^{1}$ Correspondência: luiz_paulo.aires@hotmail.com 
Ovarian vascularization is directly influenced by cyclic or gestational changes, reflecting the adaptation of the local blood supply necessary for tissue modeling and functionality at different reproductive moments. Changes in ovarian blood flow are related to angiogenic and hormonal factors, which increase or decrease tissue vascularization depending on the female's reproductive status (Köster et al., 2001).

This article aims to review the information in the literature regarding the sonographic changes in the reproductive system of bitches during different periods of the estrous cycle.

\section{The Estrous Cycle}

The canine estrous cycle consists of four phases, determined by clinical, hormonal and cytologic changes. Proestrus starts when estrogen levels begin rising, preparing the bitch's reproductive tract for mating and conception, causing vulvar swelling, bloody discharge and attracting males, but refusing to let them mount. In this period, there is development of follicles, which produce estrogen, leading to an increase in its levels (Goodman, 2001).

In the transition from proestrus to estrus, there is the surge of the luteinizing hormone (LH) and periovulatory luteinization of mature follicles, which leads to a rise of progesterone levels. This is an important feature of the canine estrous cycle and is considered a reliable physiological event in normal bitches, allowing monitoring of the estrous phase by dosing the serum levels of progesterone (Kutzler et al., 2003). In the estrus period, ovulation and conception occur, but by the time of ovulation, the oocyte has not matured and is not ready for fertilization, another singularity of the canine physiology (Lévy and Fontbonne, 2007).

Around 7 to 10 days after the LH surge, diestrus begins, the bitch does not allow the male to mount anymore and progesterone levels remain high. In the diestrus period, progesterone levels drop gradually due to corpus luteum regression in a nonpregnant bitch (Goodman, 2001).

\section{Scanning Technique}

For the evaluation of the female reproductive system, high frequency transducers (7.0 to 10.0 $\mathrm{MHz}$ ) are ideal (Webster, 2009), as they promote greater detail, allowing the visualization of follicular development. However, lower frequency transducers can be useful in assessing ovarian and uterine dimensions and in detecting pathological conditions, such as pyometra and ovarian tumors, but in cases of subtle changes, they do not provide adequate resolution (Mantis, 2008)

The exam is performed with the patient in dorsal recumbency, but both right and left lateral recumbency positions can be used to better identify the ovaries. Abdominal hair is clipped from the xiphoid appendix to the last pair of inguinal mammary glands. After that, conductive gel is applied to the animal's skin and scanning begins. Fasting is recommended, as well as the administration of antiphysetics and keeping the animal from urinating before the exam, so a full urinary bladder can provide a better acoustic window for the scan (Davidson and Baker, 2009).

The uterine body is identified in the caudal abdomen, using the urinary bladder as an acoustic window, where it is possible to visualize a hypoechoic and homogenous tubular structure between the urinary bladder and the descending colon in a longitudinal view (Fig. 1) (Barbosa et al., 2013), whereas in a transverse view it is possible to visualize the uterine body as a hypoechoic ovoid structure located dorsally to the urinary bladder and ventrally to the colon (Davidson and Baker, 2009). The uterus and uterine horns can be differentiated from intestines from the lack of luminal gas, fluid, peristalsis and different wall layering (Mantis, 2008).

Ovaries are ovoid structures located caudally to the caudal pole of the kidneys, which are important anatomical landmarks for adequate scanning. After identification of the kidneys, the transducer is moved caudally and fanned in sagittal and transverse views to locate and identify the ipsilateral ovary (Fig. 2) (Davidson and Baker, 2009; Webster, 2009).

\section{Two-dimensional ultrasonography (B-mode)}

Uterus

The sonographic appearance of the uterus and its diameter vary according to the hormonal 
Aires et al. Ultrasonographic aspects of the uterus and ovaries of bitches during the estrous cycle - paper review

influence, number of previous pregnancies and dog size, therefore, it must be considered that the uterus of large breeds and multiparous bitches might be thicker in diameter than that of a small breed and nulliparous animal (Freitas et al., 2017)

In the anestrus period, the uterine body is flat, homogeneous, with no changes in the endometrium

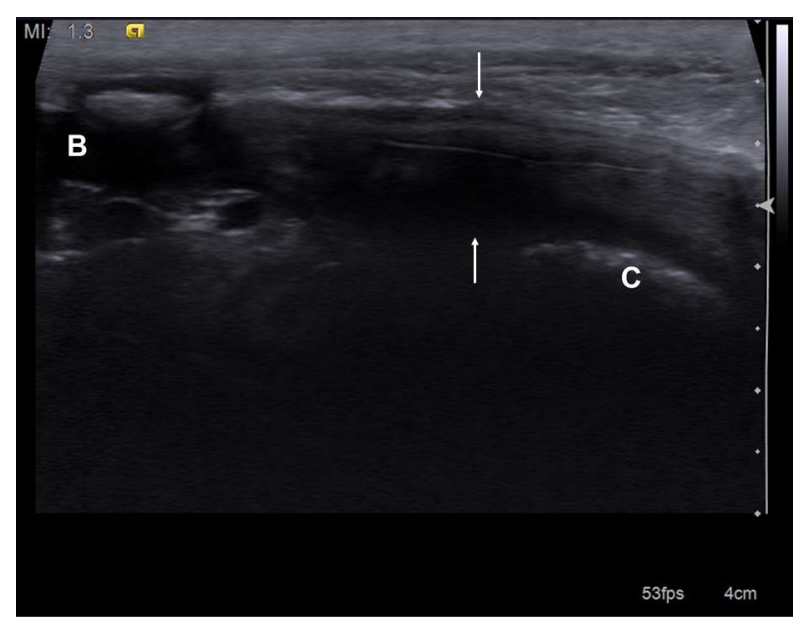

Figure 1. Longitudinal image of the uterine body (between white arrows). Note how the tubular structure is closely related to the urinary bladder (B), barely visible in the cranial portion of the image, and the descending colon (C).

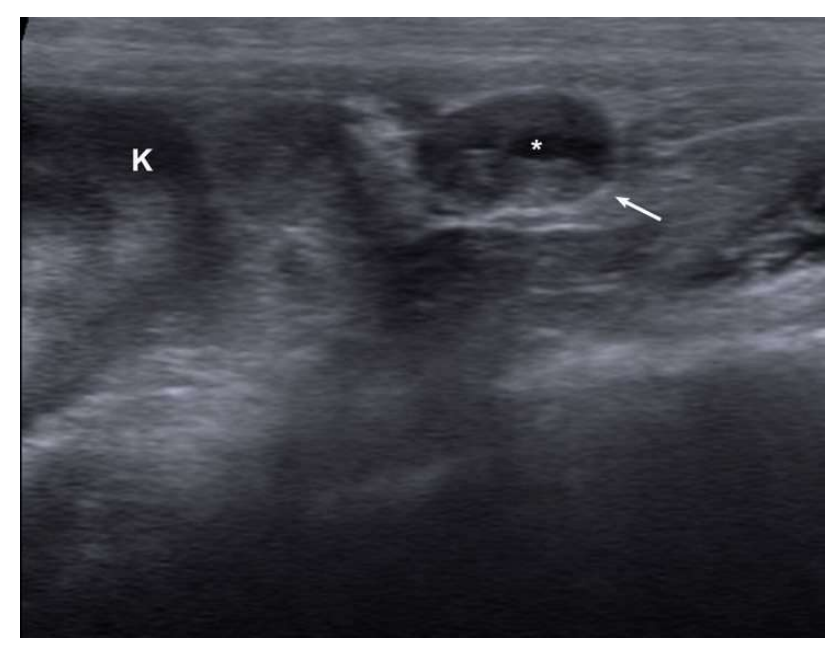

Figure 2. Longitudinal image of the left ovary of a bitch. Observe a well-defined ovoid structure (white arrow) located caudally to the left kidney $(\mathrm{K})$, predominantly isoechoic to the renal parenchyma, except for a small anechoic follicle (asterisk).

and there is no luminal content (Davidson and Baker, 2009). In this period, the uterine body diameter ranges from 5 to $8 \mathrm{~mm}$, but it may vary in pre-pubertal and nulliparous bitches (England et al., 2003), and according to animal size. During the proestrus and estrus, there is a thickening of the uterine walls due to edema caused by estrogen influence, making it possible to distinguish the layers, especially on transverse images and it is also possible to observe a discrete amount of fluid in the lumen as a fine echogenic line (Fig. 3) (Davidson and Baker, 2009; Freitas et al., 2017)

In the diestrus, the uterus has its maximum physiological thickening due to the action of progesterone, which promotes endometrial glandular development, in addition to being able to contain a small amount of fluid in the lumen (Davidson and Baker, 2009). 


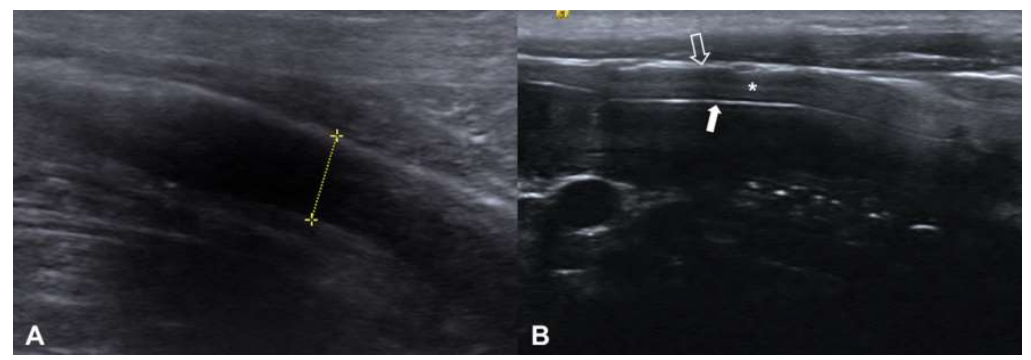

Figure 3. Appearance of the uterine body and uterine horn under hormonal influence. A. At the beginning of the proestrus, the uterus (between calipers) slightly increases in diameter and its walls become thicker. B. During mid to late proestrus and estrus, it is possible to identify the hyperplastic uterine walls and its layers. The endometrium and myometrium are identified as a central homogenous hypoechoic layer (asterisk), surrounded by the perimetrium (hollow arrow), seen as a fine hyperechoic line. Sometimes the lumen might be visible as a fine hyperechoic line between the hyperplastic uterine walls (white arrow).

In a study conducted by Freitas et al. (2017), it was possible to observe that the size of the animal and number of pregnancy and parturitions affect the uterine diameter throughout the estrous cycle. It is difficult to establish a normal parameter regarding uterine diameter in different stages of the estrous cycle because of the great variety of animal size as well as the number of pregnancy and parturition. Therefore, when evaluating the uterus, all of these factors must be taken into account and measurement alone cannot determine the reproductive status of the female, so a full breeding soundness examination is required.

Ovaries

The sonographic aspect of the ovaries also varies according to the cyclic changes of the bitch (Davidson and Baker, 2009). During the anestrus period, it can be very difficult to locate the ovaries because of their similar echogenicity to the adjacent tissues (Mantis, 2008). In this period, the ovaries are oval shaped, with echogenicity similar to that of the renal cortex and the adjacent tissue and homogeneous echotexture, but in post-pubertal bitches, it can appear somewhat heterogenous due to the presence of remnants of corpora lutea from previous cycles (Wallace et al., 1992; Lévy and Fontbonne, 2007; Mantis, 2008; Davidson and Baker, 2009).

At the beginning of the proestrus, it is possible to visualize follicular development, with the presence of anechoic structures that increase in size and quantity over the period (Wallace et al., 1992; Hayer et al., 1993; England et al., 2009). At the end of this period, the identification of the ovaries is facilitated due to the large number of follicles with dimensions increased by the greater amount of anechoic content (Fig. 4) (Lévy and Fontbonne, 2007). Bergeron et al. (2013) reported a variation of 3 to 4 follicles count by ultrasonography on each ovary, however, Lévy and Fontbonne (2007) reported that the number of follicles counted on ultrasound examination generally underestimate the real quantity. Follicle size and diameter can also vary, but usually range from 0.3 to $1.2 \mathrm{~cm}$ as they start developing and increasing their size (Mantis, 2008).

The periovulatory period is marked by a series of changes in the aspect of the ovaries, but for a better evaluation of this period, three evaluations per day are recommended (Davidson and Baker, 2009). The sonographic detection of ovulation can be performed when there is a decrease in the number of follicles from one day to the next, an event called follicular collapse (Wallace et al., 1992). However, according to Davidson and Baker (2009), follicular collapse does not occur in canine species, but Lévy and Fontbonne (2007) reported that in their experiments the follicular cavities completely disappeared in $37.5 \%$ of the bitches. Domosławska et al. (2014) observed this event in $28 \%$ of the animals. In some cases, it is possible to visualize a small amount of liquid content between the surface of the ovary and the ovarian bursa after ovulation (Fig. 5) (Lévy and Fontbonne, 2007).

The content of follicular structures undergoes a change in echogenicity and thickening of the wall, becoming hyperechoic, corresponding to the corpus hemorrhagicum and progressing to the formation of the corpus luteum (Fig. 4) (Hayer et al., 1993; Davidson and Baker, 2009) which is hypoechoic and has thicker walls than follicles (Davidson and Baker, 2009).

During the diestrus period, the ovaries may have a lobular shape, an irregular surface with the 
Aires et al. Ultrasonographic aspects of the uterus and ovaries of bitches during the estrous cycle - paper review

presence of hypoechoic corpora lutea that protrude beyond the surface of the organ (Davidson and Baker, 2009).

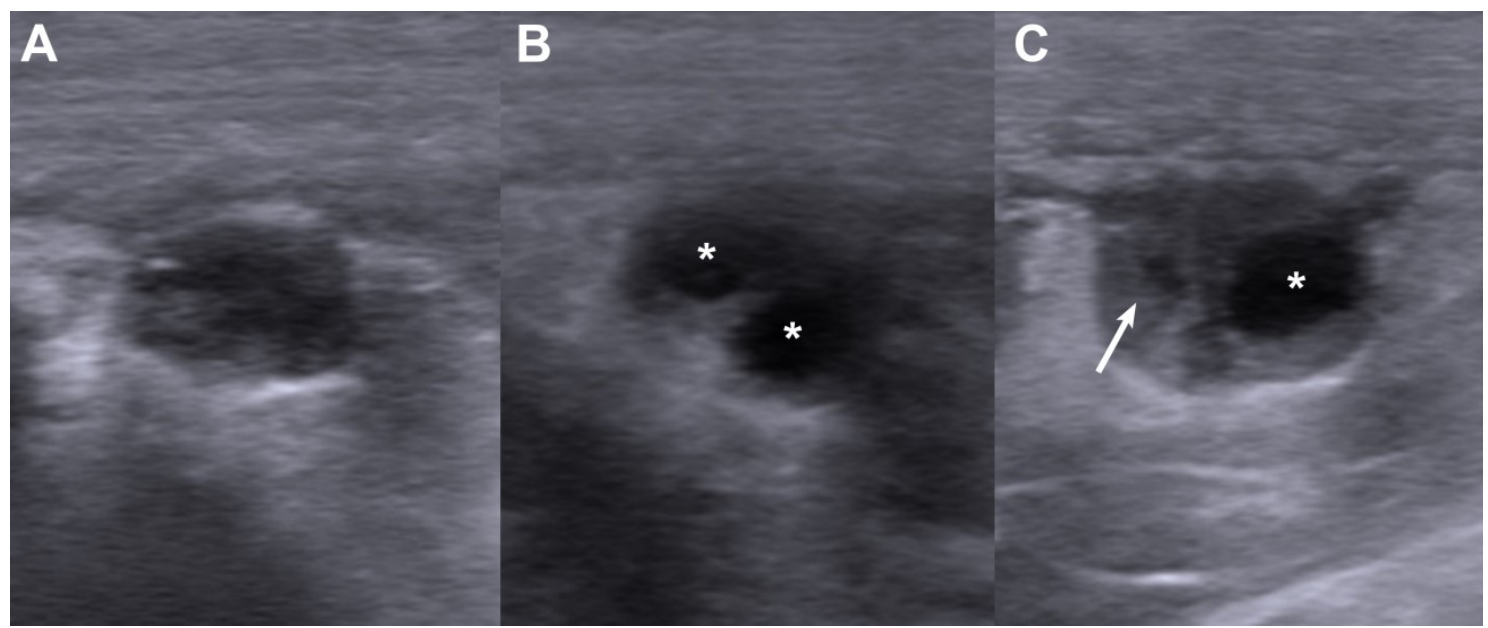

Figure 4. Follicular development during the follicular period of the estrous cycle. A. At the beginning of the proestrus, there is initial follicular development, where very small anechoic areas are visible in Bmode ultrasonography, making the ovarian parenchyma appear slightly heterogenous. B. As the follicular period progresses, at the end of proestrus, it is possible to identify follicles as large rounded structures with thin walls, filled with anechoic content. C. After ovulation, there is a decrease in the number of follicles visible (follicular collapse) and the beginning of corpus luteum formation. Note how the follicle on the left observed in A. is no longer visible in $\mathbf{C}$. as a large anechoic area as the content changes in echogenicity and walls become thicker, which corresponds to the beginning of the formation of the corpus hemorrhagicum.

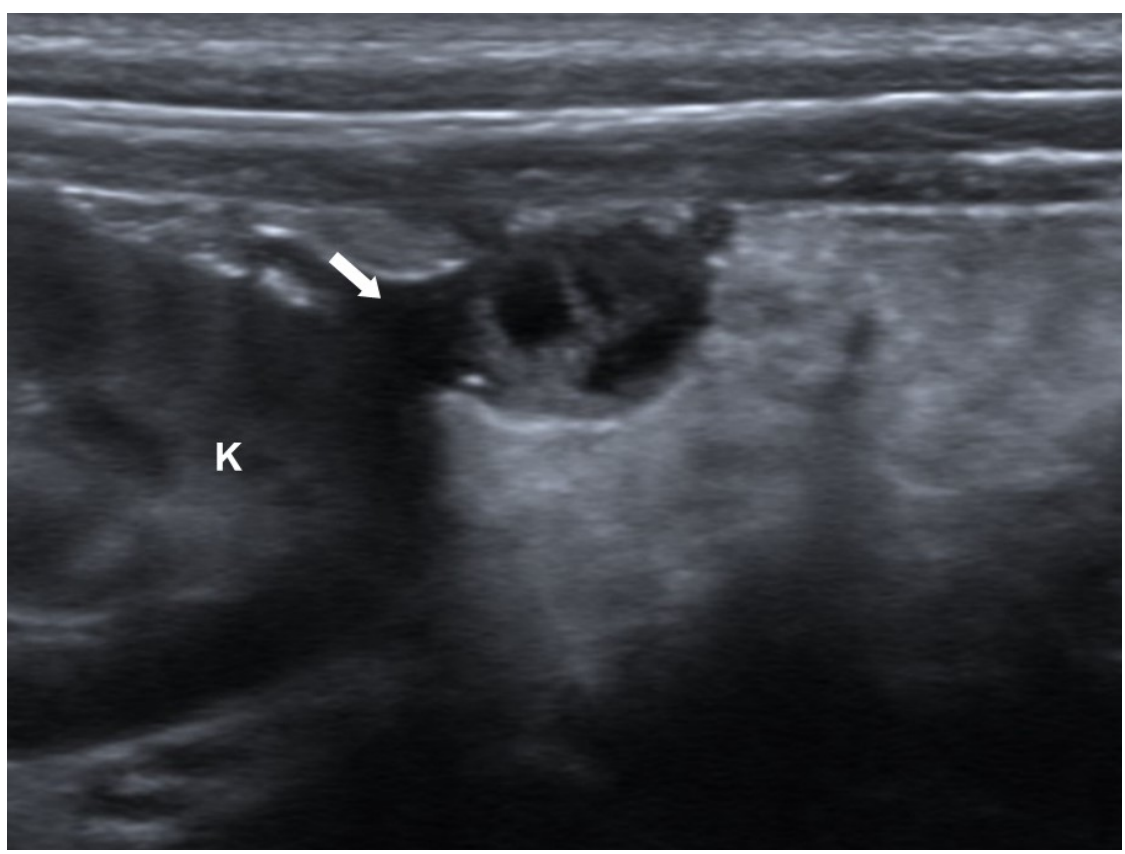

Figure 5. Fluid between the ovary and the ovarian bursa. It is possible to observe the ovary caudal to the kidney $(\mathrm{K})$ and a small anechoic content between them (white arrow). This finding indicates that ovulation has already occurred. Care should be taken not to mistake this finding as perinephric fluid collection. 


\section{Doppler evaluation}

Uterus

The uterine artery, which arises from the vaginal artery, follows ventrocaudally, penetrating the broad ligament of the uterus laterally to the cervix and proceeding cranially (Ghoshal and Nanda, 1986). Hemodynamic characteristics of uterine arteries were studied in acyclic bitches (Alvarez-Clau and Liste, 2005) and during the different periods of the estrous cycle (Barbosa et al., 2013; Freeman et al., 2013, Nogueira et al., 2017), showing changes in blood flow according to reproductive status.

For the identification of uterine arteries, it is necessary to use color Doppler mapping or even power Doppler associated with the two-dimensional mode when scanning the uterine body in longitudinal and transversal planes (Alvarez-Clau and Liste, 2005). After locating the vessel, pulsed-waved Doppler is used, placing the sample volume (gate) in the vessel lumen so that it occupies a maximum of two thirds of the vessel and making the necessary technical adjustments to obtain the appropriate spectral tracing (Freeman et al., 2013).

In the period corresponding to the anestrus, the spectral tracing of the uterine artery most often shows only a systolic peak, and occasionally a small positive diastolic flow may be evidenced (AlvarezClau and Liste, 2005) or even a reverse flow after the systolic peak (Nogueira et al., 2017).

In the proestrus and estrus phase, the morphology of the spectral tracing of the uterine artery is biphasic marked with a systolic peak followed by a small continuous flow diastolic peak (Barbosa et al., 2013; Nogueira et al., 2017).

Uterine perfusion decreases from two to three days before ovulation and remains so until ovulation occurs, consequently increasing the value of the resistivity index, being considered a hemodynamic marker of the transition between proestrus and estrus (Barbosa et al., 2013; Freeman et al., 2013; Nogueira et al., 2017). This is because before ovulation, there is a greater blood flow from the uterine artery to the ovarian artery (Barbosa et al., 2013).

In the diestrus period, the spectral tracing is presented with a high resistivity pattern, characterized by a sudden drop after the systolic peak, and a reverse flow can be evidenced (Nogueira et al., 2017).

In a study conducted by Freeman and colleagues (2013), different aspects of the spectral tracing of the uterine artery were observed, with the absence of early and late diastolic flow in older bitches, in addition to changes in velocimetric values, which present a lower final diastolic speed and, consequently, higher resistivity index values. The authors postulated that the older bitches in the study could present uterine changes that were not visible in B-mode and that these perfusion changes may be related to insufficient uterine vascularization and, consequently, infertility.

Freitas et al. (2017) reported that the dopplervelocimetric parameters from the uterine artery also vary according to the number of pregnancies, parturition and animal size. Therefore, it is important to considerer the breed, estrous cycle phase and pregnancy history when performing a Doppler assessment of the uterine artery.

Ovaries

The ovaries are supplied by the ovarian arteries, which arise from the descending aorta, pass through the cranial border of the broad ligament of the uterus to supply the gonad (Ghoshal and Nanda, 1986). Caudally, the ovarian artery emits branches, one of which is anastomosed to the uterine artery, this branch being called the uterine branch of the ovarian artery (Evans and De Lahunta, 2013).

During anestrus and at the beginning of the proestrus, color Doppler mapping is barely detectable (Köster et al., 2001). As the follicular phase progresses, the number, extent and intensity of colored pixels gradually increase (Fig. 6) making it possible to obtain dopplervelocimetric parameters from 6 days before ovulation (Fig. 7). (Köster et al., 2001; Vermeulen, 2009, Mansour et al., 2020).

In a study conducted by Vermeulen (2009), a subjective analysis showed a gradual increase in the coloured areas throughout the proestrus, reaching its maximum two days after the LH surge, which was the estimated day of ovulation. In another study, Bergeron et al. (2013) subjectively identified a significant increase of the visible blood flow from Day 0 (LH peak) to Day 1. Mansour et al. (2020) reported that on the day of ovulation, blood flow detection reaches its maximum using the Color-Doppler technique. Therefore, this method can help detect the periovulatory moment when daily scans are 

review

performed, associated with other exams such as vaginal cytology and hormonal assays.

In the periovulatory period, there is a greater perfusion of the ovarian tissue, which leads to an increase in the systolic peak velocity and the diastolic peak velocity and, consequently, a decrease in the resistivity and pulsatility indices of the intraovarian arteries (Köster et al., 2001). A peak occurs in the values of systolic peak velocity and final diastolic velocity one day before ovulation, which can remain high on the day of ovulation and up to three days after that event (Jurczak e Janowski, 2018).

Throughout the physiological luteal period, there is a gradual decrease in ovarian perfusion, evidenced by the decrease in both the number of pixels to the color mapping and the values of systolic peak speed and final diastolic speed, thus leading to an increase in resistivity indexes and pulsatility (Köster et al., 2001; Polisca et al., 2013).

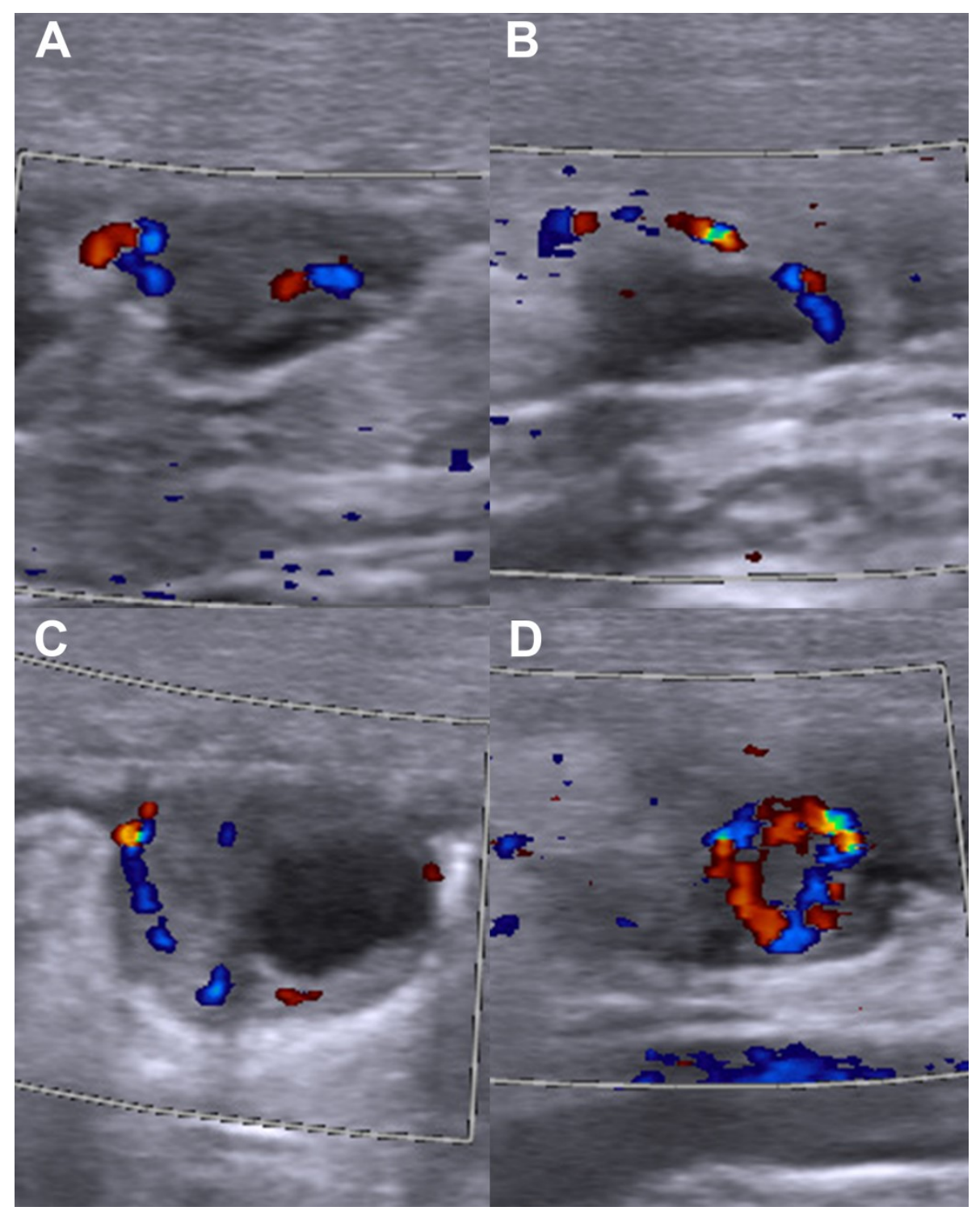

Figure 6. Color Doppler mapping of the canine ovary during the estrous cycle. A. During proestrus, there is a small detection of color pixels, which gradually increases with the progression of the period. B. At the beginning of estrus, pixel intensity increases, and blood flow is easily detected. C. At the beginning of corpus luteum formation, it is possible to detect flow around the corpus hemorrhagicum margins. D. When a corpus luteum is present, vascularization is easily seen around the structure, making it readily identified. 


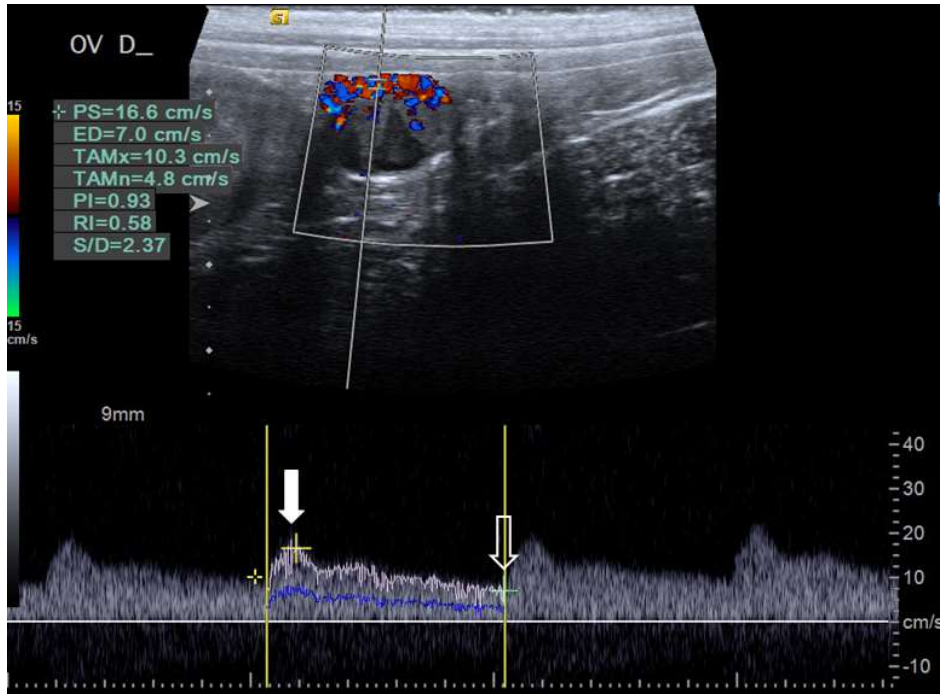

Figure 7. Triplex-Doppler of the canine ovary. A small volume sample is placed on the colored intraovarian artery, obtaining the spectral tracing of the vessel. Observe the waveform, characterized by a low-resistance spectral tracing, with a small systolic peak (white arrow) followed by a continuous and slow diastolic decrease with early to mid diastolic peak, low end diastolic velocity (hollow arrow) and complete filling of the spectral window.

\section{Conclusion}

Ultrasonography is a non-invasive imaging method that provides valuable information regarding the reproductive status of the bitch. It is possible to observe intense changes in the sonographic aspect of uterine and ovarian tissues throughout the estrous cycle due to the intense hormonal changes and their influence throughout this period, besides being possible to rule out the possibility of some reproductive diseases. The exact moment of ovulation is not yet detectable by the method, however B-mode imaging, associated with color and spectral Doppler allow the identification of the periovulatory period, but for this to be possible, serial evaluations associated with the history, clinical signs, physical examination, vaginal cytology and hormonal assays are necessary. Thus, ultrasonography should be considered a great complementary method and can be implemented in breeding soundness evaluation of the bitch as well as for monitoring ovarian activity.

\section{Acknowledgments}

The authors would like to thank the State of Sao Paulo Research Foundation (FAPESP protocol numbers: 2017/14957-6 and 2019/15282-8) and the National Council for Scientific and Technological Development for the research grant, productivity scholarship award (processes 430023/2018-9 and 309199/2017-4) and master scholarship.

\section{References}

Alvarez-Clau A, Liste F. Ultrasonographic characterization of the uterine artery in the nonestrus bitch. Ultrasound Med Biol, v.31, n.12, p.1583-1587, 2005.

Barbosa CC, Souza MB, Scalercio SRRA, Silva TFP, Domingues SFS, Silva, LDM. Ovarian and uterine periovulatory doppler ultrasonography in bitches. Pesq Vet Bras, v.33, n.9, p.1144-1150, 2013.

Bergeron LH, Nykamp SG, Brisson BA, Madan P, Gartley CJ. An evaluation of B-mode and color Doppler ultrasonography for detecting periovulatory events in the bitch. Theriogenology, v.79, n.2, p.274-283, 2013.

Boote EJ. AAPM/RSNA Physics Tutorial for Residents: Topics in US: Doppler US techniques: concepts of blood flow detection and flow dynamics. RadioGraphics, v.23, n.5, p.1315-1327, 2003.

Carvalho CF, Chammas MC, Stermann FDA, De Barros N, Cerri GG. Ultra-sonografia dúplexDoppler na avaliação morfológica e hemodinâmica das artérias aorta e mesentérica cranial em cães. Braz 
Aires et al. Ultrasonographic aspects of the uterus and ovaries of bitches during the estrous cycle - paper review

J Vet Res Anim Sci, v.45, n.1, p.24-31, 2008.

Davidson AP, Baker TW. Reproductive ultrasound of the bitch and queen. Top Companion Anim Med, v.24, n.2, p.55-63, 2009

Domosławska A, Jurczak A, Janowski T. Progesterone level does not distinguish the different course of canine ovulation determined by ultrasonography. Pol J Vet Sci, v.17, n.2, p.293-297, 2014.

England GCW, Russo M, Freeman SL. Follicular dynamics, ovulation and conception rates in bitches. Reprod Domest Anim, v.44, p.53-58, 2009.

England GCW, Yeager AE, Concannon PW. Ultrasound imaging of the reproductive tract of the bitch. In: Concannon PW, England GCW, Vestegen III J, Linde Forsberg C. Recent advances in small animal reproduction, International Veterinary Information Service, 2003. Available in: https://www.ivis.org/library/recent-advances-small-animal-reproduction/ultrasound-imaging-ofreproductive-tract-of-bitch. Access in: March. 29, 2021.

Evans HE, De Lahunta A. Miller's anatomy of the dog. Elsevier Health Sciences, 2013.

Freeman SL, Russo M, England GCW. Uterine artery blood flow characteristics assessed during oestrus and the early luteal phase of pregnant and non-pregnant bitches. Vet J, v.197, n.2, p.205-210, 2013.

Freitas LA, Mota GL, Silva HVR, Silva LDM. Two-dimensional sonographic and Doppler changes in the uteri of bitches according to breed, estrus cycle phase, parity, and fertility. Theriogenology, v.95, p.171-177, 2017.

Goodman, M. Ovulation timing: Concepts and controversies. Vet Clin North Am Small Anim Pract, v.31, n.2, p.219-235, 2001.

Ghosal NG, Nanda BS. Coração e Artérias do Carnívoro In: Getty, R. Sisson/Grossman anatomia dos animais domésticos, Ed. 5, v.2 p.1497-1550, 1986.

Hayer P, Günzel-Apel AR, Lüerssen D, Hoppen HO. Ultrasonographic monitoring of follicular development, ovulation and the early luteal phase in the bitch. J Reprod Fertil Suppl, v.47, p.93-100, 1993.

Jurczak A, Janowski T. Arterial ovarian blood flow in the periovulatory period of GnRH-induced and spontaneous estrous cycles of bitches. Theriogenology, v.119, p.131-136, 2018.

Köster K, Nautrup CP, Günzel-Apel AR. A Doppler ultrasonographic study of cyclic changes of ovarian perfusion in the Beagle bitch. Reproduction, n.3, p.453-461, 2001.

Kutzler MA, Mohammed HO, Lamb SV, Meyers-Wallen VN. Accuracy of canine parturition date prediction from the initial rise in preovulatory progesterone concentration. Theriogenology, v.60, n.6, p. 1187-1196, 2003.

Lévy X, Fontbonne A. Determining the optimal time of mating in bitches: particularities. Rev Bras Reprod Anim, v.31, n.1, p.128-134, 2007.

Mantis P. Ultrasonography of the urinary and genital system of the dog and cat. Iranian J Vet Surg 2008; Suppl for the 2nd ISVS and 7th ISVAR: 63-71.

Mansour A, Abdeldjelil MC, Bougherara H, Khellaf D, Aissi A. Color-doppler ultrasonography to predict the moment of ovulation in the bitch. Adv Anim Vet Sci, v.8, n.7, p.782-787, 2020.

Nogueira IB, Almeida LL, Angrimani DSR, Brito MM, Abreu RA, Vannucchi CI. Uterine haemodynamic, vascularization and blood pressure changes along the oestrous cycle in bitches. Reprod Domest Anim, v.52, p.52-57, 2017.

Polisca A, Zelli R, Troisi A, Orlandi R, Brecchia G, Boiti C. Power and pulsed Doppler evaluation of ovarian hemodynamic changes during diestrus in pregnant and nonpregnant bitches. Theriogenology, v.79, n.2, p.219-224, 2013.

Vermeulen MAE. Ovarian Color-Doppler Ultrasonography to Predict Ovulation in the Bitch. Master's thesis - Louisiana State University, 2009. Available in: https://dspace.library.uu.nl/handle/1874/35523 Acess in: March 292021.

Wallace SS, Mahaffey MB, Miller DM, Thompson FN, Chakraborty PK. Ultrasonographic appearance of the ovaries of dogs during the follicular and luteal phases of the estrous cycle. Am J Vet Res, v.53, n.2, p.209-215, 1992.

Webster N. Ultrasonography of the urogenital tract in dogs and cats. In Pract, v.31, n.5, p.210-217, 2009. 